\title{
The effect of socio-demographic factors and sources of sex information on romantic love levels among Jimma university students
}

Fentie Ambaw

\begin{abstract}
Background: Romantic love levels determine the way individuals select their mate and what they expect from their sexual partners.

Objective: To determine the effect of selected sociodemographic characteristics and sources of sex information on romantic love levels.

Methods: A quantitative survey was conducted on 828 randomly selected regular students of Jimma University using a piloted questionnaire in May 2008.

Results: The median age of the respondents was 20 (mean= 20.8, SD=2). They had considerably high romantic love levels with Western type passion-focused ideals and myths about love and mate selection. Socio-demographic factors including gender, religion, ethnicity, place of origin (urban/rural), and level of education did not have a statistically significant effect on the romantic love level of the respondents. Romantic love levels were higher for those students who habitually watch love films, read love related materials or attend love related radio programs, but the effect sizes were small (Eta squared 0.0054, 0.0218, and 0.0131 respectively) indicating the presence of the romantic ideals in the culture itself.

Conclusions: Romantic ideals of love were found in the culture and provoked by mass media products. Further community based investigations, and IEC (information, education, and communication) works are recommended. [Ethiop.J.Health Dev. 2009;23(1):34-39]
\end{abstract}

\section{Introduction}

According to Robert Sternberg's triangular theory of love, love has three components: intimacy (bondedness), passion (sexual consummation) and commitment (maintaining love). According to this theory romantic love is love without commitment $(1,2)$. Romantic love causes a great trouble in forming long lasting relationships. The moment the fires of romantic love begin to die down, those trapped by their belief in romantic love turn a way from their partner searching for the ideal mate. Because of the fact that no such ideal exists, they will be continuing the search for ever $(1,2,3)$. The increasingly exerted influence of schools and mass media on human sexuality has brought romantic love in to a cultural construct $(2,3,4)$.

In Ethiopia, although efforts are being made to promote reproductive health, unwanted pregnancies, abortions, sexually transmitted infections including HIV/AIDS are not declining proportionally $(5,6,7)$. Premarital sex is increasing even at ages earlier than ever before, divorce rates are shooting up, and prostitution has flourished in major towns and cities $(7,8,9)$. This may be, at least partly, attributable to the existence of romantic ideals and myths about love that influence sexual relationships and mate selection in the general public. Until the time of this study, there was no documented information about the romantic love levels of young people in Ethiopia.
This study was designed to determine the level of romantic love among Jimma University students along with the socio-demographic factors and sources of sex information influencing it. The knowledge of romantic standards with the socio-demographic factors and sources of sex information influencing them is extremely important in the prediction and control of behaviors related to sexuality.

\section{Methods}

The study was conducted in Jimma University main campus in May 2008. A cross-sectional quantitative survey was conducted on a total of 828 regular students of all years (523 males and 303 females, 2 missed sex) selected randomly using the complete list of the students as a sampling frame. Extension and graduate students were not included in this study.

The variance of the dependent variable, level of romantic love among the students, was used to determine the sample size required to estimate mean level of romantic love. To estimate the population for "romantic love level,” a 30 item, five-point Likert scale adopted from Cox F.D (2) to fit the typical male-female partnership of Ethiopia, was administered in December 2007 on 54 randomly selected students of Jimma University (who were not included in the final study). The scale was composed of items that indicate both realistic and passion focused beliefs as well as myths about love. The results had shown that the sample variance was 188, and the

Department of Health Education and Behavioral Sciences, Public Health Faculty, P.O. Box 5225, E-mail fentambawWyahoo.com, Jimma University, Jimma, Ethiopia 
reliability of the scale was 0.73 using Crombach alpha test. This variance had been used as a crude estimate of the population variance in the following formula

Sample size was then determined using a confidence level of $95 \%$, margin of error of one, variance of 188 , and a contingency of $15 \%$. The following formula (10) had been used:

$$
\mathbf{n}=\frac{(1.96)^{2} \mathrm{~V}}{\mathbf{M}^{2}}
$$

$\mathbf{M}^{2}$ where, $\mathbf{n}$ is the required sample size, 1.96 is the tabular value of the $95 \%$ confidence level, $\mathbf{V}$ is the variance of romantic love in the study population (here, $\mathbf{V}=188$ ), and $\mathrm{M}$ is the accepted margin of error (here,

$\mathbf{M}=1)$.

$\mathrm{n}=\underline{(1.96)^{2} \times 188}$

$$
1
$$

$\mathbf{n}=$ 723. With $15 \%$ contingency (109), the final sample size becomes $\mathbf{8 3 2}$.

The dependent variable of the study, romantic love was operationalized as a positive attitude towards passionfocused beliefs and myths about love on the scale; it was measured at an interval level of measurement. The independent variables of the study were sociodemographic characteristics of the students (age, sex, level of education, faculty, place of origin (urban/ rural), ethnicity, religion, church or mosque attending habit, marital status, and history of parental divorce) and sources of sex information (being exposed to love films, love related radio programs, or love related reading materials at least once a week, the students' perception of the general theme of information obtained from school life (elementary to current level), and the students' experience of discussing sexual matters with parents).

The data was collected using a piloted and pre-coded questionnaire translated to Amharic by two language experts. Appropriateness of translation was checked by back translation by another expert. The questionnaires were filled in rooms prepared for that purpose and were collected as soon as they were completed by the respondents. Supervision was strict to ensure independence of responses. Informed consent was obtained from everyone of the respondents before data collection and the proposal was evaluated by Jimma University for ethicality. Trained instructors of Jimma University participated during the data collection process.

The data was analyzed using SPSS for windows version 13. One-way-between-groups ANOVA with Post-hoc comparisons, independent-samples t-test, and descriptive statistics were computed to determine the effect of sociodemographic factors and sources of sex information on romantic love levels of the respondents. Effect sizes for ttests and ANOVAs were determined using Eta squared values. Statistical significance was considered when pvalue was less than 0.05 .

\section{Result}

Socio-demographic characteristics of respondents

Out of the randomly selected 832 students, 828 (99.52\%) have responded for the questionnaire. The respondents were at the age ranging between 17-34 years with median 20 (mean $=20.8, \mathrm{SD}=2$ ). Most of them were single (788 (96.1\%)) and 112 (13.6\%) of them had their parents divorced. Five hundred twenty two (64.1\%) were urban in origin, 321 (40.7\%) were from Amhara ethnic group, 475 (62.9\%) were Orthodox in religion, and 663 (87.1\%) had the habit of frequently attending church or mosque. The level of education and the faculty of respondents have been shown in Table 1.

Table 1: Some socio-demographic characteristics of

\begin{tabular}{|c|c|c|}
\hline \multicolumn{3}{|l|}{$\begin{array}{l}\text { Characteristics } \\
\text { Sex }(n=826)\end{array}$} \\
\hline Male & 523 & 63.3 \\
\hline Female & 303 & 36.6 \\
\hline \multicolumn{3}{|l|}{ Marital status $(n=820)$} \\
\hline Single & 788 & 96.1 \\
\hline Married & 32 & 3.9 \\
\hline \multicolumn{3}{|l|}{ Place of origin $(n=822)$} \\
\hline Urban & 527 & 64.1 \\
\hline Rural & 295 & 35.9 \\
\hline \multicolumn{3}{|l|}{ Ethnicity $(n=788)$} \\
\hline Amhara & 321 & 40.7 \\
\hline Oromo & 211 & 26.8 \\
\hline Tigre & 89 & 11.3 \\
\hline Guragie & 79 & 10 \\
\hline Others* & 88 & 11.2 \\
\hline \multicolumn{3}{|l|}{ Religion $(n=755$ ) } \\
\hline Orthodox & 475 & 62.9 \\
\hline Protestant & 155 & 20.5 \\
\hline Muslim & 89 & 11.8 \\
\hline Others ${ }^{\star *}$ & 36 & 4.8 \\
\hline \multicolumn{3}{|l|}{$\begin{array}{l}\text { Church/Mosque attending habit } \\
(\mathrm{n}=761)\end{array}$} \\
\hline Yes & 663 & 87.1 \\
\hline No & 98 & 12.9 \\
\hline \multicolumn{3}{|l|}{ Level of education $(n=818)$} \\
\hline Year- one & 303 & 37.0 \\
\hline Year - two & 237 & 29.0 \\
\hline Year - three & 198 & 29.2 \\
\hline Year four/or above & 80 & 9.8 \\
\hline \multicolumn{3}{|l|}{ Faculty $(n=826)$} \\
\hline Medical Sciences & 139 & 16.8 \\
\hline Public Health & 157 & 19.0 \\
\hline Business and Economics & 136 & 16.5 \\
\hline Humanities and Social Sciences & 50 & 6.1 \\
\hline Technology & 74 & 9.0 \\
\hline Education & 177 & 21.4 \\
\hline Natural Sciences & 56 & 6.8 \\
\hline & 37 & 4.5 \\
\hline \multicolumn{3}{|l|}{ Parental divorce $(n=821)$} \\
\hline Yes & 112 & 13.6 \\
\hline No & 709 & 86.4 \\
\hline
\end{tabular}
the respondents, May 2008

* = include Catholics, no religion, 'waqeffata

** = include Wolita, Hadya, Gamo, and others 


\section{Exposure of respondents to sex information}

In this study, 312 (41\%) respondents watch love films $400(52.8 \%)$ respondents listen to love related radio programs, and 368 (49.8\%) respondent read love materials at least once a week. Four hundred eighty six (64.2\%) respondents learned about sex in the classroom. Among those who reported the content of the classroom sex education as perceived by them, 199 (43.1\%) reported "abstain from sex until marriage; if you do not want to abstain, take measures to avoid STDs and unwanted pregnancy". The self reports have also revealed that 295 (39.8\%) respondents have discussed sexual matters with their parents (Table 2).

\section{Romantic love level}

Out of 828 respondents, 826 (99.8\%) have completed the romantic love scale. The total score of the respondents ranged from 44 (the most realistic response of the respondents) to 140 (the most romantic response of the respondents), with a median of 94 (mean $=94.39, \mathrm{SD}=$ 12.22).

Table 2: Exposure of respondents to sex information, May 2008

\begin{tabular}{|c|c|c|}
\hline Exposure to sex information & Number & Percent \\
\hline \multicolumn{3}{|l|}{ Watching love films ( $n=761)$} \\
\hline Yes & 312 & 41.0 \\
\hline No & 449 & 59.0 \\
\hline \multicolumn{3}{|l|}{ Listening to love related radio programs ( $n=757)$} \\
\hline Yes & 400 & 52.8 \\
\hline No & 357 & 47.2 \\
\hline \multicolumn{3}{|l|}{ Reading love related materials $(n=739)$} \\
\hline Yes & 368 & 49.8 \\
\hline No & 371 & 50.2 \\
\hline \multicolumn{3}{|l|}{ Sex education in the classroom $(n=757)$} \\
\hline Yes & 486 & 65.2 \\
\hline No & 271 & 35.8 \\
\hline \multicolumn{3}{|l|}{ Discussion of sexual matter with parents ( $n=741)$} \\
\hline Yes & 295 & 39.8 \\
\hline No & 446 & 60.2 \\
\hline \multicolumn{3}{|l|}{ Perceived content of classroom sex education ( $n=462)$} \\
\hline - Abstain from sex until marriage & 181 & 39.2 \\
\hline \multirow{2}{*}{$\begin{array}{l}\text { Abstain from sex until marriage; if you do not want to abstain, } \\
\text { take measures to prevent STDs and unwanted pregnancy }\end{array}$} & 199 & 43.1 \\
\hline & 82 & 17.7 \\
\hline
\end{tabular}

After checking for normality of distribution and homogeneity of variance, independent-samples t-test was done to determine whether the level of romantic love scores differ with gender, place of origin (rural versus urban), mosque or church attending habit, discussion of sexual issues with parents, and parental divorce. None of these groups have shown a statistically significant difference in romantic love score at 0.05 levels.

Respondents who read love related materials or listen to love related radio programs or watch love films at least once a week were more romantic than their counter parts $(\mathrm{P}=0.000, \mathrm{P}=0.002, \mathrm{P}=0.044$ respectively). However, the effect sizes for all the differences were small (Eta squared $=0.0218,0.0131$, and 0.0054 respectively). In this study, the romantic love score of respondents who got classroom sex education has not shown a statistically significant difference from the respondents that did not get classroom sex education $(\mathrm{P}=0.305)$ (Table 3$)$.
After checking for the assumptions of homogeneity of variance and normality of distribution, one-way between -groups ANOVA was conducted to explore the impact of religion, ethnicity, educational level, faculty of respondents, and perceived content of message of classroom sex education on romantic love scores of the respondents. Findings showed that there was no statistically significant difference in romantic love level among the different religions $(\mathrm{P}=0.133)$, ethnicities $(\mathrm{P}=$ 0.53), levels of education ( $\mathrm{P}=0.253)$, and perception of the content of classroom sex education $(\mathrm{P}=0.80)$. Although this study has shown a statistically significant difference in romantic love levels among the students of different faculties, $(\mathrm{P}=0.015)$, Post-hoc comparisons using Tukey HSD test indicated that only Natural Science faculty's respondents were more romantic than Education faculty respondents $(\mathrm{P}=0.018)$. The actual difference of these two groups was also found to be small (Eta squared $=0.021)$ (Table 4$)$. 
Table 3: Comparison of the mean romantic love scores of different groups of respondents using the independent samples t-test, May, 2008

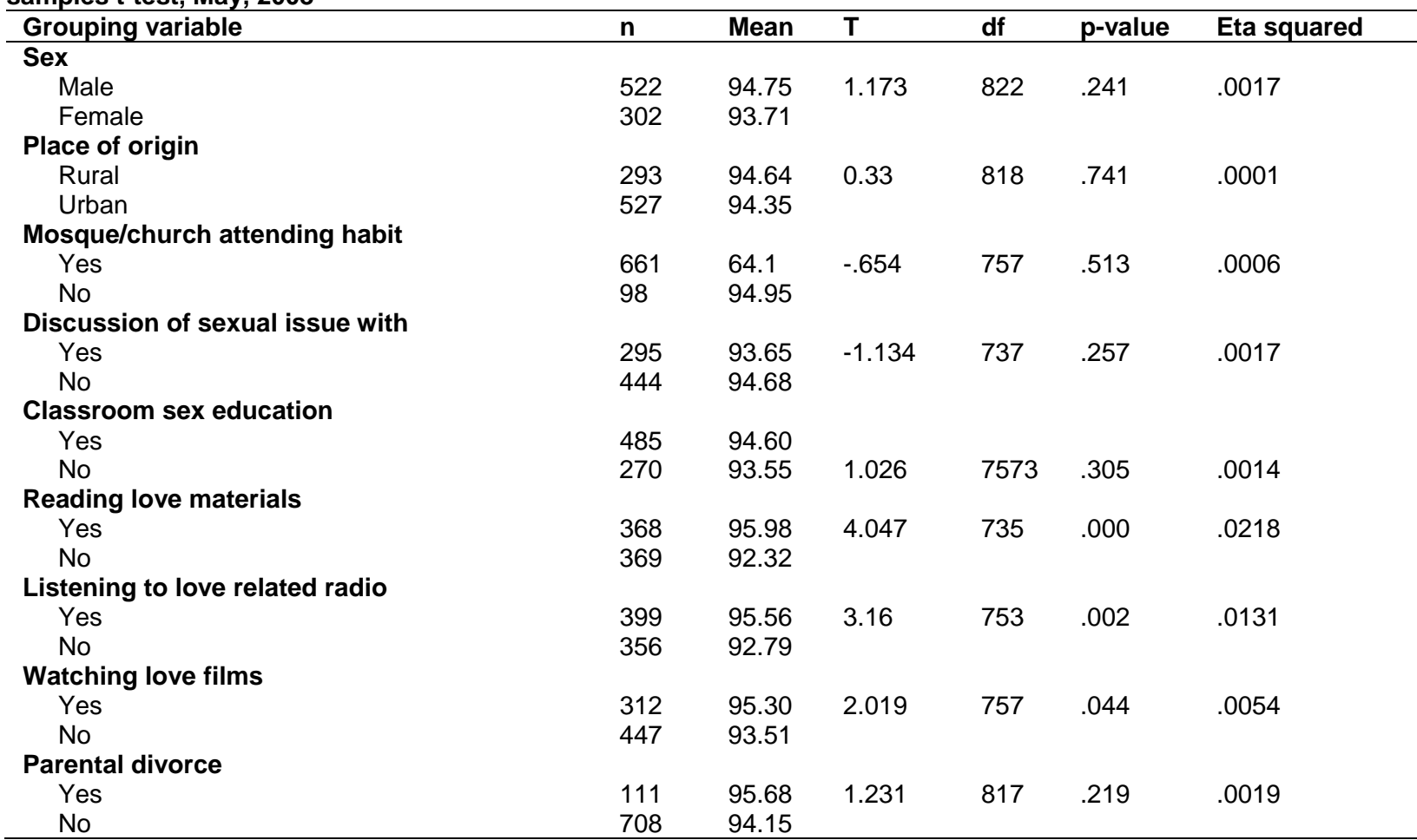

Table 4: Comparison of mean romantic love scores of different groups of the respondents using one-way betweengroups ANOVA

\begin{tabular}{|c|c|c|c|c|c|}
\hline Grouping variable & Mean & Df & $\mathbf{F}$ & P-value & $\begin{array}{l}\text { Eta } \\
\text { squared }\end{array}$ \\
\hline \multicolumn{6}{|l|}{ Religion } \\
\hline Orthodox & 94.97 & $(3,749)$ & 1.87 & .133 & .0074 \\
\hline Protestant & 93.47 & & & & \\
\hline Muslim & 92.7 & & & & \\
\hline Others & 91.56 & & & & \\
\hline \multicolumn{6}{|l|}{ Ethnicity } \\
\hline Amhara & 93.94 & $(4,781)$ & .793 & .53 & .0040 \\
\hline Oromo & 94.78 & & & & \\
\hline Tigre & 96.23 & & & & \\
\hline Guragie & 93.47 & & & & \\
\hline Others & 94.48 & & & & \\
\hline \multicolumn{6}{|l|}{ Level of Education } \\
\hline Year - one & 94.43 & $(3,812)$ & 1.363 & .253 & .0050 \\
\hline Year - two & 93.93 & & & & \\
\hline Year - three & 95.66 & & & & \\
\hline Year four/or above & 92.65 & & & & \\
\hline \multicolumn{6}{|l|}{ Faculty } \\
\hline Medical Sciences & 93.44 & $(7,816)$ & 2.509 & .015 & .0210 \\
\hline Public Health & 93.56 & & & & \\
\hline Business and Economics & 94.57 & & & & \\
\hline Humanities and Social Sciences & 92.62 & & & & \\
\hline Technology & 95.04 & & & & \\
\hline Education & 97.27 & & & & \\
\hline Natural Sciences & 90.95 & & & & \\
\hline Law & 93.19 & & & & \\
\hline \multicolumn{6}{|l|}{ Content of classroom sex education } \\
\hline $1^{*}$ & 95.09 & $(2,458)$ & .223 & .80 & .0010 \\
\hline $2^{\star \star}$ & 94.49 & & & & \\
\hline $3^{\star \star \star}$ & 95.46 & & & & \\
\hline
\end{tabular}


Because the distribution of age of the respondents was not reasonably normal, Pearson's product moment correlation could not be done to see the relationship between age and romantic love score. Spearman's Rank Order Correlation coefficient has shown that there was no statistically significant relationship between age of the respondents and their romantic love scores $(\mathrm{r}=0.043, \mathrm{P}=$ 0.227) (table not shown). Some of the common romantic ideals and myths about love reported by the respondents have been shown on table 5 .

Table 5: Some of the common romantic beliefs/ myths of the respondents, May 2008

\begin{tabular}{lc}
\hline Romantic beliefs/ myths & Number (Per cent ) \\
$\mathbf{n}=\mathbf{8 2 6}$ & $641(77.6 \%)$ \\
\hline It does not matter if you marry after you have known your partner for only a short time as & $617(74.7 \%)$ \\
long as you are in love & $481(58.2 \%)$ \\
Love does not make sense; it just is. & $448(54.2 \%)$ \\
Most divorces probably result from falling out of love rather than failing to adjust & $427(51.7 \%)$ \\
Regardless of other factors if you truly love a person, that is enough to marry him/her & $424(51.3 \%)$ \\
Love at first sight is often the deepest and most enduring type of love & $345(41.8 \%)$ \\
Love is more of a feeling than a relationship & $274(33.2 \%)$ \\
Usually there are one or two people in the world whom you could really love and be happy & $220(26.6 \%)$ \\
with & \\
Most people truly love only once during their lives & $210(25 \%)$ \\
Jealousy varies directly with love; the more you are in love, the greater your tendency to & 220 \\
become jealous & \\
Somewhere there is an ideal mate for most people &
\end{tabular}

\section{Discussion}

In this study, very high scores of romantic love levels have been observed. Sociological surveys indicate that romantic love is a universal phenomenon of all human cultures $(1,3,11)$. Widely held beliefs such as considering love as a feeling rather than a relationship and taking love as the only criteria for marriage are indicators of the contemporary Western notions of love focusing on passion $(2,3)$. Myths reported by the respondents such as taking 'love at the first sight' as a marker of 'true love,' indicate that the focus of the respondents is on the passion part of love. Evidences show that such love becomes increasingly difficult to maintain long term relationships such as marriage as most of the life activities that make a relationship succeed are not romantic in nature (2).

The level of romantic love has not shown a statistically significant difference among different religions, ethnicities, genders, place of origin (urban/rural), level of education, it rather showed a normal distribution among the study subjects. This may indicate that the romantic beliefs and myths are existing widely in the general public from which the students have come. The finding that showed age had no correlation with romantic love level did not allow conclusion as this study had not taken the full range of age.

An increased level of romantic love has been observed among the students who frequently read love related materials, listen to love related radio, or watch love films, but the actual difference explained by these factors was small. The small variance explained by these mass media products which are assumed to be the most important ways of disseminating romantic ideals may strengthen the idea that the factors responsible for most of the variance exist with in the culture. Whether students with high romantic love levels were motivated to be exposed to those factors or those who were exposed to those factors had increased romantic love levels can not be concluded from this cross-sectional study; however, the effect of mass media on romantic love level can not be neglected $(2,3,4)$.

Previous evidences showed that parental divorce makes children more romantic (12). This research has not supported that probably because divorce in Ethiopia is not easy leading to unhappily continued marriage which has almost the same effect. Similarly classroom sex education and discussion of sexual issues with parents had not a statistically significant effect on romantic love level. This may be attributed to the lack of the necessary details in both the parental discussion and classroom sex education.

Students of Education Faculty had slightly higher romantic love levels (Eta squared $=0.021$ ) when compared to students of Natural Sciences Faculty. Differences in the degree of exposure to love related reading materials may be responsible for the observed small difference.

In conclusion, the respondents had considerably high romantic love levels with Western type passion-focused ideals and myths of love which are forming an attitude that can lead to difficulty of establishing long lasting relationships such as marriage. There was no statistically significant difference in romantic love levels among the different socio-demographic groups of the students. Although romantic love levels were higher for those students who frequently read love related materials, watch films, or listen to love related radio programs, the 
effect of these mass media products was small indicating that the source for most of the variance exists with in the culture. Further community based investigations and strengthening IEC (information, education, and communication) services to minimize romantic ideals and myths about love among the general public are recommended.

\section{Acknowledgement}

I would like to express my thanks to Jimma University for funding this research project. I am also grateful to participants and data collectors of this study. I am indebted to Mr. Yohanis Adgeh (MA), Mr. Lemma Nigatu (MA), and Mr. Tibebe Kasahun (BA) for translating the questionnaire to Amharic.

\section{References}

1. Wagner KV. The science of love 2008. URL: http://www.wikimediafoundations.org/ Accessed on Oct. 20, 2007.

2. Cox FD. Human intimacy: marriage, the family, and its meaning. $9^{\text {th }}$ ed. USA: Wadsworth 2002. 61- 70.

3. Park J. Separating lust and love. 2006. URL: http://www.tc.umn.edu/ Parkx032/; Accessed on Oct. 20, 2007.

4. Picinni F, Palme J, Palme G. Sex education for teens 2007. URL: http://web4health.inf/en Accessed on Nov. 02, 2007.
5. Mwambazi WC. \& Yadeta M. Monitoring and evaluation of HIV/AIDS/STD- Ethiopia (Date not specified). URL: http://heart-intl.net/HEART/ Internat/comp/ethiopia, Accessed on Sept. 24, 2007.

6. Bnet Research Center. High dangerous abortion rate in Ethiopia 2002. URL: http://findarticles.com/p/ articles/mi_hb264/is_200211, Accessed on Sept. 16, 2007.

7. Hailegnaw E. Poverty, war and the AIDS epidemic in Ethiopia 1992. URL: http://gateway.nlm.nih/ gw/cmd Accessed on Dec. 04, 2007.

8. Central Statistical Agency of Ethiopia. Demography and Health Survey 2005, Addis Ababa.

9. Tilson D., Larsen U. Divorce in Ethiopia: the impact of early marriage and childlessness. Journal of Biosocial Science 2000; 32:355-372. Cambridge University Press. url: http://journals.cambridge.org/ action/displayabstract; Accessed on Dec. 30, 2007.

10. Kumar R. Research methodology: a step-by-step guide for beginners. London: SAGE 1999. 165

11. Henery G. thinking about romantic/erotic love 1997. URL: http://find articles.com/p/articles/mi_qa3658 Accessed on Nov. 08, 2007.

12. Jacquet. Marital relationships of young adults from divorced families 2001. URL: http://students.usm. maine.edu/cortney.bailey/home.html Accessed on Sept. 15, 2007. 